\title{
Are Adults Better Behaved Than Children? Age, Experience, and the Endowment Effect.
}

\author{
William T. Harbaugh* \\ University of Oregon \\ and N.B.E.R. \\ Kate Krause \\ University of New Mexico \\ Lise Vesterlund \\ Iowa State University
}

May 13, 2000

\begin{abstract}
:
We find that large increases in age do not reduce the endowment effect, supporting the hypothesis that people have reference-dependent preferences which are not changed by repeated experience getting and giving up goods.

JEL Classification: D1

Keywords: Endowment effect, prospect theory, reference dependence, experimental economics.

Acknowledgments: We thank the principal, teachers and students who made this project possible. We also thank Rachel Croson and seminar participants at the 1998 ESA meetings for helpful comments; John Hobbs for his work on an earlier version of this project; and Josha Antos and Kristin Hutchens for expert research assistance. NSF Grants SBR-9810847 and SBR9810835 funded this research.
\end{abstract}

* Corresponding author. Department of Economics, University of Oregon, Eugene, Oregon 97403-1285. Tel (541) 346-1244, fax (541) 346-1243, e-mail harbaugh@ oregon.uoregon.edu. 
Are Adults Better Behaved Than Children?

Age, Experience, and the Endowment Effect.

\section{Introduction}

The minimum compensation people are willing to accept (WTA) in return for giving up a good they already possess exceeds the amount that they are willing to pay (WTP) to acquire the same good. When offered an opportunity to trade, people tend to keep the good that they have. This "endowment effect" is particularly large when people are asked hypothetical questions about values of non-market goods, but it has also been found in experiments involving real transactions with common market goods, as well as in real life decisions.

One explanation for the endowment effect is that people have reference-dependent preferences, defined over changes in the consumption of goods rather than over levels. Another is that this reluctance to trade is simply a mistake. If it is a mistake, then people who exhibit endowment effects are trading too little, and losing out on beneficial trades. As people gain experience in markets they should learn from these mistakes, make them less frequently, and the endowment effect should decrease. On the other hand, if preferences are reference-dependent, the reluctance to trade is not a mistake, and experience should not lead to a reduction.

Unfortunately the literature does not agree on how the endowment effect changes with experience. Knez et al. (1985), Coursey et al. (1987), Brookshire and Coursey (1987) and Shogren et al. (1994) have used repetition to examine how reported WTA and WTP change as subjects gain familiarity with the experimental protocol. While they found that the measures converge, Kahneman, Knetsch, and Thaler (1990) used a different incentive-compatible mechanism and found that it does not. 
Besides being inconclusive, we argue that this line of research addresses whether subjects learn to respond to a particular mechanism rather than the more general question of how real world experience with transactions changes the endowment effect. In this paper we examine the effect of changes in actual market experience on the endowment effect.

In order to obtain large variations in market experience, we use a subject pool that includes both five to ten-year-old grade school children and college undergraduates. The accumulated market experience of a typical five-year-old is substantially different from that of a ten-year-old, and the difference between these children and undergraduates is even more dramatic. For example, only $9 \%$ of our $3^{\text {rd }}$ and $5^{\text {th }}$ grade subjects reported that they bought things with their own money on a weekly basis.

\section{Experimental Design}

Our experiments were conducted during the fall and winter of 1998 on a total of 163 subjects from New Mexico. We collected data on 125 children from kindergarten, third-grade, and fifth-grade classrooms at a public elementary school, and from 38 undergraduates in introductory economics classes at the University of New Mexico. While we did not collect data on individual ages, with rare exceptions children start kindergarten at age 5, and start fifth grade at age ten. The undergraduate subjects' average age was 20.

We used a simple protocol from Knetsch (1989). Subjects were given one good and then asked if they wanted to keep it or trade it for another. This procedure was repeated for 3 of the 4 pairs of goods described in Table 1. Children chose from the first 3 pairs of goods, and undergraduates from the last 3 . The children's goods were chosen because they were familiar, widely available in stores, and appealed to both boys and girls. The goods in a pair were roughly 
of equivalent value. During the experiment it was clear that the appeal to children of the goods increased from the first to the third pair. The undergraduates were not given the first pair of children's goods, since we doubted these goods would appeal to adults. Their last pair was a choice between two 100-gram Swiss chocolate bars, or a coffee mug with the university logo on it, similar to the goods that Knetsch and others have used.

[Table 1 about here.]

We randomly divided the subjects in each classroom into two groups. Subjects in one group were given one good, and those in the other group were given the other good. Along with the item, each subject was given a tag. A sample of the other good was then passed among each group. After inspecting the item, the students chose to either keep their original good (by placing a blue sticker on the tag it came with) or to trade it for the other good (by placing a yellow sticker on the tag). The second and third rounds were played exactly as the first, but with different pairs of goods. Every subject and every class received the pairs of goods in the same order, except for the difference for undergraduates noted above. The protocol is available from the authors.

\section{Results}

When given a choice between two goods, an endowment effect exists if the probability that a person chooses, say, good A is higher if they were initially endowed with good A than if they were endowed with good B. We define the "endowment boost" as the average across the two goods of the increase in the likelihood that a person chooses a good when they are endowed 
with it, relative to being endowed with the other good. That is, if $p_{j \mid i}$ denotes the probability of choosing good $j$ when endowed with good $i$, then the endowment boost equals $1 / 2 \frac{p_{1 \mid 1}}{p_{1 \mid 2}}+1 / 2 \frac{p_{2 \mid 2}}{p_{2 \mid 1}}$.

The children's choices for each of the three pairs are presented in Tables 2.1 through 2.3. The rows indicate the good that a subject was endowed with, while the columns indicate which good they chose. We report both $n_{i j}$, the number of subjects endowed with good $i$ who choose $\operatorname{good} j$, and $p_{j \mid i}$, the probability a person chooses good $j$, conditional on having been endowed with good $i$. We say an endowment effect exists if the endowment boost is greater than 1 . Formally we use Fisher's Exact Test of the null hypothesis that endowment has no effect on which good a person chooses. ${ }^{1}$ The probability values for the test statistics and the endowment boost are reported for each pair.

[Tables 2.1 through 2.3 about here.]

For every good, the likelihood of choosing the good increases when the child is endowed with it. Fisher's Exact Test rejects the null hypothesis of no endowment effect for all pairs. Furthermore, the effect is quite large. In table 2.1, for example, the first row shows that 24 of the 60 subjects who were endowed with good A kept it, while 36 switched to good B. The second row shows that of the 65 subjects who were endowed with good B, 6 switched to A and 59 kept B. While good A was not very popular relative to good B, it was considerably more likely to be chosen when a subject was endowed with it than when not, and the same was true of good B. For the A\&B pair of goods, children on average are 2.9 times more likely to choose the good they are

1 This test, from Fisher (1925), is done by using the binomial distribution to calculate the exact probability of getting the observed results, or results more contradictory to the null, if the null is true. 
endowed with than the good they are not. The analogous number is 1.9 and 2.5 for the subsequent pairs. We are unable to say anything about the effect of repetition on the size of the endowment effect for two reasons. First, it is possible that any effect is driven by differences in the pairs of goods, rather than by repetition. Second, the Zelen Test has a probability value of 0.51 , so we cannot reject the hypothesis that the endowment boosts are equivalent across goods. ${ }^{3}$

Next we look at the data from our undergraduate subjects. Tables 3.1 through 3.3 show that, as with the children, an endowment effect exists for all three pairs of goods.

[Tables 3.1 through 3.3 about here.]

We then examine whether age is related to the endowment effect. Table 4 shows the endowment boosts for all four pairs of goods by grade level so that we can look at differences in the boosts by age. While the pair 1 boost for the kindergartners is undefined because none of the subjects endowed with good B switch, the endowment effect is obviously large. While the thirdgraders appear to be the least susceptible to the endowment effect, their behavior is not significantly different than that of the other age groups. Formally, for pairs 1, 2, and 3, the Zelen Test cannot reject the null hypothesis that the endowment effects are the same for all grades. The

3 The Zelen Test (Zelen, 1971) is an exact test, derived from the binomial probabilities, for the homogeneity of the odds-ratios $\frac{\frac{n_{11}}{n_{11}+n_{12}}}{\frac{n_{12}}{n_{11}+n_{12}}} / \frac{\frac{n_{21}}{n_{21}+n_{22}}}{\frac{n_{22}}{n_{21}+n_{22}}}$ across treatments (or pairs, in our case), where $n_{i j}$ is the number of observations in row $i$, column $j$ for a given treatment. 
probability values are $0.091,0.16$, and 0.75 respectively. Only the test for pair 1 is even marginally significant.

[Table 4 about here.]

\section{Conclusion}

We examine the endowment effect in children and adults and find strong evidence for the existence of the effect in all our subjects. We find no evidence that the endowment effect decreases with age. Fifth-graders are, on average, twice as old as kindergartners and have accumulated substantially more market experience. Despite this age difference, the strength of the endowment effect did not differ significantly between the two groups. This lack of a difference is even more striking when comparing children and college undergraduates. The undergraduates are 4 times as old as the kindergartners, and are far more familiar with shopping, trading, and getting and giving up goods. Yet the endowment effect for the two groups is nearly the same. Of course, there are many differences between children and undergraduates besides market experience, and so we cannot be totally sure that there might not be an age related difference in some other variable that is offsetting the effect of increased market experience. Still, this possibility seems remote.

We argue that these results are inconsistent with the argument that the endowment effect is a mistake or a transitory anomaly related to market inexperience. If that were true, then the relatively unsophisticated children would have kept their initial endowments at higher rates than did the adults in this study. We believe the most reasonable interpretation of these results is that 
they support reference-dependent preferences. The endowment effect appears to be a "real" part of preferences, rather than a mistake that diminishes with experience and learning. 


\section{References:}

Brookshire, David S., and Don L. Coursey, "Measuring the Value of a Public Good: An Empirical Comparison of Elicitation Procedures," American Economic Review, 77(4), 1987, pp. 554-66.

Coursey, Don L., John J. Hovis, and William D. Schulze, "The Disparity Between Willingness to Accept and Willingness to Pay Measures of Value," The Quarterly Journal of Economics, 102(3), 1987, pp. 679-690.

Fisher, R. A., Statistical Methods for Research Workers, Oliver and Boyd, Edinburgh, (1925).

Kahneman, Daniel, Jack L. Knetsch, and Richard Thaler, "Experimental Tests of the Endowment Effect and the Coase Theorem," Journal of Political Economy, 98(6), 1990, pp. 13251348.

Knetsch, Jack L., "The Endowment Effect and Evidence of Nonreversible Indifference Curves," American Economic Review, 79(5), 1989, pp. 1277-1284.

Knez, Peter, Vernon L. Smith, and Arlington W. Williams, "Individual Rationality, Market Rationality, and Value Estimation," American Economic Review, 75(2), 1985, pp. 397402.

Shogren, Jason F., Seung Y. Shin, Dermot Hayes, and James B. Kliebenstein, "Resolving Differences in Willingness to Pay and Willingness to Accept," American Economic Review, 1994, pp. 255- 270.

Zelen, M., "The Analysis of Several 2 x 2 Contingency Tables," Biometrika, 58(1), 1971, pp. 129-137. 
Table 1: The goods

\begin{tabular}{ccl}
\hline Pair & ID Letter & Description \\
\hline 1 & A & $\begin{array}{l}\text { Key chain with a toy alien attached } \\
\text { Small irregularly shaped super ball }\end{array}$ \\
& B & Mechanical pencil \\
& C & $\begin{array}{l}\text { Highlighter marker } \\
3\end{array}$ \\
D & E & 6- function electronic calculator \\
& F & Box of 8 colored "overwriting" markers \\
& Chocolate bars (2) \\
4 & Goffee mug
\end{tabular}


Table 2.1: Children's choices, Pair 1

\begin{tabular}{lllll}
\hline & \multicolumn{3}{c}{ Good kept } \\
\cline { 2 - 4 } & & $\mathrm{A}$ & $\mathrm{B}$ & Total \\
\hline \multirow{2}{*}{ Endowment } & $\mathrm{A}$ & $24\left(\mathrm{p}_{\mathrm{A} \mid \mathrm{A}}=0.40\right)$ & $36\left(\mathrm{p}_{\mathrm{B} \mid \mathrm{A}}=0.60\right)$ & 60 \\
& $\mathrm{~B}$ & $6\left(\mathrm{p}_{\mathrm{A} \mid \mathrm{B}}=0.092\right)$ & $59\left(\mathrm{p}_{\mathrm{B} \mid \mathrm{B}}=0.91\right)$ & 65 \\
\hline Total & 30 & 95 & 125 \\
\hline $\begin{array}{l}\text { Endowment boost }=2.9 \\
\text { p-value of hypothesis of no endowment effect }=0.000\end{array}$ & \\
\hline
\end{tabular}

Table 2.2: Children's choices, Pair 2

\begin{tabular}{lllll}
\hline & \multicolumn{4}{c}{ Good kept } \\
\cline { 2 - 4 } & & $\mathrm{C}$ & $\mathrm{D}$ & Total \\
\hline \multirow{2}{*}{ Endowment } & $\mathrm{C}$ & $47\left(\mathrm{p}_{\mathrm{C} \mid \mathrm{C}}=0.76\right)$ & $15\left(\mathrm{p}_{\mathrm{D} \mid \mathrm{C}}=0.24\right)$ & 62 \\
& $\mathrm{D}$ & $30\left(\mathrm{p}_{\mathrm{C} \mid \mathrm{D}}=0.48\right)$ & $33\left(\mathrm{p}_{\mathrm{D} \mid \mathrm{D}}=0.52\right)$ & 63 \\
\hline Total & 77 & 48 & 125 \\
\hline $\begin{array}{l}\text { Endowment boost }=1.9 \\
\text { p-value of hypothesis of no endowment effect }=0.002\end{array}$ \\
\hline
\end{tabular}

Table 2.3: Children's choices, Pair 3

\begin{tabular}{lllll}
\hline & & \multicolumn{3}{c}{ Good kept } \\
\cline { 3 - 4 } & & $\mathrm{E}$ & $\mathrm{F}$ & Total \\
\hline \multirow{2}{*}{ Endowment } & $\mathrm{E}$ & $39\left(\mathrm{p}_{\mathrm{E} \mid \mathrm{E}=0.70)}\right.$ & $17\left(\mathrm{p}_{\mathrm{F} \mid \mathrm{E}=0.30)}\right.$ & 56 \\
& $\mathrm{~F}$ & $19\left(\mathrm{p}_{\mathrm{E} \mid \mathrm{F}=0.28)}\right.$ & $50\left(\mathrm{p}_{\mathrm{F} \mid \mathrm{F}=0.72)}\right.$ & 69 \\
\hline Total & 58 & 67 & 125 \\
\hline $\begin{array}{l}\text { Endowment boost }=2.5 \\
\text { p-value of hypothesis of no endowment effect }=0.000\end{array}$ \\
\hline
\end{tabular}


Table 3.1: Undergraduates' choices, Pair 2

\begin{tabular}{lllll}
\hline & & \multicolumn{3}{c}{ Good kept } \\
\cline { 2 - 4 } & & $\mathrm{C}$ & $\mathrm{D}$ & Total \\
\hline \multirow{2}{*}{ Endowment } & $\mathrm{C}$ & $12\left(\mathrm{p}_{\mathrm{C} \mid \mathrm{C}}=0.63\right)$ & $7\left(\mathrm{p}_{\mathrm{D} \mid \mathrm{C}}=0.37\right)$ & 19 \\
& $\mathrm{D}$ & $3\left(\mathrm{p}_{\mathrm{C} \mid \mathrm{D}}=0.16\right)$ & $16\left(\mathrm{p}_{\mathrm{D} \mid \mathrm{D}}=0.84\right)$ & 19 \\
\hline Total & 15 & 23 & 38 \\
\hline $\begin{array}{l}\text { Endowment boost }=3.1 \\
\text { p-value of hypothesis of no endowment effect }=0.003\end{array}$ & \\
\hline
\end{tabular}

Table 3.2: Undergraduates' choices, Pair 3

\begin{tabular}{lllll}
\hline & & \multicolumn{3}{c}{ Good kept } \\
\cline { 2 - 4 } & & $\mathrm{E}$ & $\mathrm{F}$ & Total \\
\hline \multirow{2}{*}{ Endowment } & $\mathrm{E}$ & $9\left(\mathrm{p}_{\mathrm{E} \mid \mathrm{E}=0.47)}\right.$ & $10\left(\mathrm{p}_{\mathrm{F} \mid \mathrm{E}=0.53)}\right.$ & 19 \\
& $\mathrm{~F}$ & $2\left(\mathrm{p}_{\mathrm{E} \mid \mathrm{F}=0.11)}\right.$ & $17\left(\mathrm{p}_{\mathrm{F} \mid \mathrm{F}=0.89)}\right.$ & 19 \\
\hline \multirow{2}{*}{ Total } & & 11 & 27 & 38 \\
\hline
\end{tabular}

Endowment boost $=3.1$

$\mathrm{p}$-value of hypothesis of no endowment effect $=0.013$

Table 3.3: Undergraduates' choices, Pair 4

\begin{tabular}{lllll}
\hline & & \multicolumn{3}{c}{ Good kept } \\
\cline { 2 - 4 } & & $\mathrm{G}$ & $\mathrm{H}$ & Total \\
\hline \multirow{2}{*}{ Endowment } & $\mathrm{G}$ & $12\left(\mathrm{p}_{\mathrm{G} \mid \mathrm{G}}=0.63\right)$ & $7\left(\mathrm{p}_{\mathrm{H} \mid \mathrm{G}}=0.37\right)$ & 19 \\
& $\mathrm{H}$ & $2\left(\mathrm{p}_{\mathrm{G} \mid \mathrm{H}=0.11)}\right.$ & $17\left(\mathrm{p}_{\mathrm{H} \mid \mathrm{H}=0.89)}\right.$ & 19 \\
\hline \multirow{2}{*}{ Total } & & 14 & 24 & 38 \\
\hline
\end{tabular}

Endowment boost $=4.2$

p-value of hypothesis of no endowment effect $=0.003$ 
Table 4: Endowment boosts by grade.

\begin{tabular}{|c|c|c|c|c|c|}
\hline \multirow[b]{2}{*}{ Grade } & \multicolumn{5}{|c|}{ Endowment boosts } \\
\hline & Pair 1 & Pair 2 & Pair 3 & Pair 4 & Average \\
\hline $\mathrm{K}$ & $*$ & 2.5 & 3.7 & $* *$ & \\
\hline 3 & 1.5 & 1.1 & 2.0 & $* *$ & 1.5 \\
\hline 5 & 6.6 & 3.0 & 2.2 & $* *$ & 3.9 \\
\hline Undergraduate & $* *$ & 3.1 & 3.1 & 4.2 & 3.5 \\
\hline Average & & 3.2 & 2.8 & 4.2 & \\
\hline $\begin{array}{l}\text { p-value of test that } \\
\text { endowment boosts are } \\
\text { the same across grades }\end{array}$ & 0.091 & 0.16 & 0.75 & $* *$ & \\
\hline
\end{tabular}

